\title{
Cause Analysis and Countermeasures on 40 cases of Nursing Disputes Resulting from the Withdrawal of Needle of Venous Transfusion in Pediatrics Outpatient Department
}

\author{
Jianying $\mathrm{Xu}{ }^{*}$ \\ Transfusion Room, The Affiliated Children's Hospital of Medical School of Zhenjiang University, Hangzhou, \\ Zhenjiang 310003, China
}

\begin{abstract}
Objective: To enhance the nursing quality and the satisfaction degree of nursing service by analyzing, rectifying and reforming the causes of nursing disputes in 40 cases of venous transfusion in pediatric outpatient department resulting from withdrawal of needle. Methods: In view of the dispute causes, strengthen the training of young nurses, enhance the nurses' communication skills, establish standard process of withdrawal of needle, encourage the nurses to take early stage psychological assessment and intervention of the patients and their parents who are discontent, and intensify the health communication and education. Results: Strict enforcement of the process of withdrawal of needle, conduct early stage psychological assessment and intervention on the patients and their parents, and effective health communication and education can effectively reduce the occurrence rate of disputes. Conclusion: Enforce the process of withdrawal of needle strictly, take timely psychological assessment and intervention on the patients and their parents, strengthen the nurses' service awareness, and implement the health communication and education can ensure the safety of patients' transfusion and the nurses', thus effectively enhance the nursing quality and the satisfaction degree of nursing services in pediatrics venous transfusion.
\end{abstract}

\author{
KEYWORDS \\ Pediatrics \\ Venous transfusion \\ Nursing disputes \\ Psychological intervention
}

\begin{abstract}
1. Introduction
Venous transfusion is one of the most common nursing works in outpatient department of pediatrics, and is also an important treatment method on patients. There are a great number of transfusion, the workload is large, the nurses are insufficient, and struggle to cope with, which affect the nursing quality to a certain extent, and there exist many potential disputes when the nurses withdraw the
\end{abstract}

Copyright $\odot 2014$ Jianying Xu

doi: $10.18686 /$ jn.v3i1.1

Received: March 15, 2014; Accepted: June 6, 2014; Published online: August 23, 2014

This is an open-access article distributed under the terms of the Creative Commons Attribution Unported License (http://creativecommons.org/ licenses/by-nc/4.0/), which permits unrestricted use, distribution, and reproduction in any medium, provided the original work is properly cited. ${ }^{\star}$ Corresponding author: Transfusion Room, The Affiliated Children's Hospital of Medical School of Zhenjiang University, Hangzhou, Zhenjiang 310003, China. E-mail: jianying_x88@163.com needle at the end of transfusion. Therefore in the management of pediatrics outpatient transfusion, if the nurses' operation is not standard or the nurses lack the awareness of nurses-patients disputes, health education, or good communication skills, there will exist all kinds of conflicts and disputes, which threats seriously the safety of transfusion and nurses. In recent years, there is a growing trend in the disputes caused by the withdrawal of needle at the end of the venous transfusion in the pediatrics outpatient department. In this article the author analyzes retrospectively the causes which resulted in the nursing disputes caused by the withdrawal of needle between April 2013 and April 2014, comes up with corresponding nursing intervention measures, and makes a report as follows.

\section{General data}

2.1. Clinical data

The data originated from the reception processing records 
in the transfusion room and relevant departments in the hospital, and the number of the processed complaint incidents caused by the withdrawal of needle was 40 between April 2013 and April 2014.

\subsection{Results}

The causes which resulted in disputes when withdrawing the needle include: poor service attitude in 6 cases, poor communication in 8 cases, negligence in operation in 12 cases, the insufficient health communication and education in 12 cases, and other reasons in 2 cases.

\section{Causes analysis}

\subsection{Nursing personnel aspects}

Personnel structure: 16 nurses were involved, including 4 nurses-in-charge, 3 primary nurses, 9 nurses. The occurrence and causes of disputes are indicated in Table 1 and 2.

There is a substantial increase in the proportion of junior nurses, and lack of nursing experience of young nurses is a major reason which results in nursing disputes. From Table 1 it is can be seen that $70 \%$ of the disputes resulting from the withdrawal of needle are caused by the nurses with a working experience within 5 years. Secondly, because a substantial part of the young nurses are the only-children in their families, they have very strong self-consciousness and independent personality, they do not have sufficient service awareness, and they believe that they are all equal and cannot understand why they must accommodate themselves to the patients. They do not realize that as medical staffs, they should cultivate the professional quality of "treating the patient as the center". Table 2 shows that $70 \%$ of the disputes resulting from the withdrawal of needle is caused by the 80 s nurses.

\subsubsection{The misused words and the deficient communi- cation between nurses and patients}

The environment is very noise, and the workload is very large in the pediatrics, so the nurses are irritable, sometimes they only focus on the nursing operation, and neglect the necessary comforting and encouragement on the patients, pay no attention to the parents' emotions and psychology, which makes them unsatisfactory. Sometimes the nurses do not make good takeover with the parents after withdrawing the needle, which leads to bleeding in the needle hole after the cotton ball falls. The nurses do not take into consideration the parents' love in the children, and always just blame the parents why they do not press and hold the puncture point. The cause of disputes in 6 cases of 40 cases in this group was that the cotton balls were not pressed and held appropriately and the nurses did not explain timely, it was because that the adhesive tape pulled more hair when withdrawing the needle in 4 cases, the parents were unsatisfied but the nurses said that it was normal, and the parents thought the nurse were indifferent to the children and had no love, which resulted in the disputes $[1,2]$.

\subsubsection{Insufficient transposition consideration by the nurses}

The establishment of the relationship between nurses and patients in pediatrics transfusion is similar to the relationship between emergency nurses and patients, namely the short establishment time, high requirements and more conflicts [3].The parents care about the children, and hope that they are treated timely, and have no patience to wait, while because the nurses handle all various patients who will be transfused in the transfusion room all the year, and are accustomed to the patients' basic conditions. In this situation, if the nurses have no good consciousness of service, it will often stimulate the occurrence of conflicts. There are 6 cases in this group due to the weak service consciousness of nurses when withdrawing the needle, and when encountering the parents who do not understand, the nurses usually quarrel with the parent, which leads to

Table 1. Causes resulting in nursing disputes by the nurses with different working ages.

\begin{tabular}{cccccc} 
Working Ages & $\begin{array}{c}\text { Poor Attitude } \\
\text { Cases Percentage }\end{array}$ & $\begin{array}{c}\text { Poor Communication } \\
\text { Cases Percentage }\end{array}$ & $\begin{array}{c}\text { Negligence in Operation } \\
\text { Cases Percentage }\end{array}$ & $\begin{array}{c}\text { Health Communication } \\
\text { and Education } \\
\text { Cases Percentage }\end{array}$ & $\begin{array}{c}\text { Other Reasons } \\
\text { Cases Percentage }\end{array}$ \\
\hline $1-3$ Years & $3(7.5 \%)$ & $6(15 \%)$ & $6(15 \%)$ & $6(15 \%)$ & $1(2.5 \%)$ \\
$3-5$ Years & $1(2.5 \%)$ & $2(5 \%)$ & $3(7.5 \%)$ & $2(5 \%)$ & - \\
$5-10$ Years & $1(2.5 \%)$ & - & $1(2.5 \%)$ & $2(5 \%)$ & $1(2.5 \%)$ \\
$>10$ Years & $1(2.5 \%)$ & - & $2(5 \%)$ & $2(10 \%)$ & - \\
\hline
\end{tabular}

Table 2. Causes resulting in nursing disputes by the nurses with different ages.

\begin{tabular}{cccccc}
\hline Age & $\begin{array}{c}\text { Poor Service Attitude } \\
\text { Cases Percentage }\end{array}$ & $\begin{array}{c}\text { Poor Communication } \\
\text { Cases Percentage }\end{array}$ & $\begin{array}{c}\text { Negligence in } \\
\text { Operation } \\
\text { Cases Percentage }\end{array}$ & $\begin{array}{c}\text { Health Communication } \\
\text { and Education } \\
\text { Cases Percentage }\end{array}$ & $\begin{array}{c}\text { Other Reasons } \\
\text { Cases Percentage }\end{array}$ \\
\hline $20-31$ years old & $4(10 \%)$ & $8(20 \%)$ & $8(20 \%)$ & $7(17.5 \%)$ & $1(2.5 \%)$ \\
$31-40$ years old & $1(2.5 \%)$ & - & $2(5 \%)$ & $2(5 \%)$ & $1(2.5 \%)$ \\
Above 40 years old & $1(2.5 \%)$ & - & $2(5 \%)$ & $3(7.5 \%)$ & - \\
\hline
\end{tabular}


disputes.

\subsubsection{The nurses lack professional knowledge and op- erational skills}

The nurses think the withdrawal of needle is the easiest nursing work, so do not perform according to the nursing process strictly, and neglect various nursing skills when withdrawing the needle, which leads to the patients' injuries resulting from the inappropriate operation, and complaints. There are 8 cases in this group due to the patients skin scratches resulting from the nurses' disoperation, which leads to disputes.

\subsubsection{The insufficient health communication and edu- cation}

The nurses' workloads are large, and have no extra time to make health communication and education for the parents of inform them about the corresponding medical knowledge. There are 6 cases the reasons of which are that due to the patients were not cooperative or the nurses did not inform the parents of the notices of pressing and holding the needle eyes, leading to the falling of the cotton balls and bleeding around the needle eyes, so the parents thought the nurses' method of withdrawal of needles was wrong, which leads to the disputes. And the nurses were violently assaulted in 3 cases and were timely prevented by the security.

\subsection{Social factors}

Because of the continuous development of medical reform, the continuous strengthening of the legal awareness of patients, and the new trend of nurses-patients relationship, the requirements of the parents on the nursing service quality is increasingly high, which leads to more and more conflicts of venous transfusion in pediatrics outpatient, and the causes are more and more complex and sophisticate. The parents' requirements are not only limited to the treatment of the doctors, and the taking the needles from the nurses, but they have a deeper level of demands. In the nursing work, if the nurses do not change the mode of nursing timely, they cannot adapt to the changing needs of patients, which leads to the disputes.

Due to the misleading of the medical science by the media publicity, the public's attitude towards medical science is changing from the traditional "thanksgiving" and "tolerance" to current "precaution" and "blame", resulting into prejudice on the medical institutions by some parents. When the treatment effects do not meet their expectations, they will treat the nurses as the vent to release their temper. While the transfusion room is the last stop of pediatrics outpatient, and the environment is noisy, the waiting time is long, plus they may encounter some displeasure in other phrases of the treatment, some parents think that the nurses can be bullied easily, so at the end of the transfusion when they encounter some displeasure, they will air their grievances on the nurses [4].

\section{Countermeasures}

\subsection{Allocate human resources reasonably according} to the need

Schedule the shifts according to the need at peak hour, and due to the large workload of the itinerating nurses in the transfusion room, the nurses usually neglect the effective communication with the parents and the health communication and education of the patients and parents because they are very busy. Discuss the problems in the working, and analyze and come up with rectifying and reforming measures, improve the service process. Arrange more nurse to itinerate as far as possible if the staff situation is allowed, and make flexible shift schedule according to the peak hour in the transfusion room, allocate human resources reasonably. Arrange 2-3 itinerating nursing in the peak hour of transfusion, and open more venous transfusion platform to reduce the queuing time of the patients, shorten the process of the treatment, enhance the satisfaction degree of the patients and their parents, and reduce the occurrence of nursing disputes [5].

\subsection{Regulate the process of withdrawal of needle}

Make full use of the collective strengthen and brainstorm through providing advice by the nurses, select the process which is corresponded with the clinic practical operation, take modeling needle-withdrawing training in the department study, apply the most scientific method of withdrawal of needles. Use normalized standard language when withdrawing the needle, come up with the ten love words and ten prohibited words in the transfusion room. Make a procedure for the nurse to follow in the process of nursing, so the head nurses have guidance to follow, and according to this, the head nurses can determine whether there is any violation against the operation procedure. Establish the review mechanism of complaints and disputes.

\subsection{Improve the application materials, and strive to provide convenient medical supplies}

In view of the disputes that have occurred, on one hand, the adhesive tape are easy to come off due to the sweating, and the adhesive tape is easy to lead to allergy, which results in repeated puncture in vein. The parents are unhappy at first, so later on they are more prone to conflict. And on other hand, when the nurses tear off the adhesive tape, the tape will bring more hair of the patients because the adhesive tape is very sticky, and the patients will cry and restless due to the pains, so the parents think the nurses have no love and withdraw the needle violently. In accordance with the two reasons, select the $3 \mathrm{M}$ non-woven breathable tape wide tape which is not sticky, reduce the rate of repuncture on the scalp vein, and temporarily no skin allergic events occur. Effectively reduce the complaints resulting from these reasons. 
4.4. Strengthen the service awareness, improve the nurses-patients communication skills, and take protection according to law

When the children are sick, the parents must be very upset, so the nurses must understand the parents' mood sufficiently. The nurses should strengthen their self-cultivation continuously when facing part of the parents' anger and blame, and view all the things around themselves in a tolerant and philanthropic way. Strengthen the young nurses' service awareness and work responsibility, and make the complaint rate connected with the appraisal. Implement the traditional imparting, helping and guiding mode combined with the new training mode of systematic training of communication skills in the department, and carry out the discussion and improvement on the complaint case actively in the entire department, put every nurse in the position of being complained, bring the collective wisdom into full play and come up with the rectification and reform. The staffs in the department should learn the legal knowledge, strengthen the nursing staffs' legal awareness, and make comments and analysis on part of the disputes in the legal respective, combine the theory and practice, and make sure that all the nursing activities can be protected by law [6].

\subsection{Make timely assessment and intervention of un- satisfied parents}

The nurses should take courses about psychological counseling, and the nurses should make timely assessment on the patients and take corresponding intervention measures when the patients encounter unexpected situations in the process of transfusion. In this group, after the new procedure of withdrawal of needle was established, it occurred in 1 case that the parents could not control the patient who was very frisky, which resulted in repeated venous punctures, and the parents were on the edge of anger and selfaccusation, and displayed strong dissatisfaction and resentment, so the nurse who withdrew the needle assessed timely and took corresponding intervention measures, explained and comforted patiently. In view of the characteristics of the frisky patient, the nurse suggested that the patient should take venous indwelling. After obtaining the permission from the parents, made good shifts with venous indwelling, and succeeded in indwelling. The rest 3 bags of liquid were finished safely by the patients and the entire liquid was finished safely in the second and third day. At the end of the transfusion of 3 days, the patient thanked the nurse happily and praised her.

\subsection{Strengthen health communication and education}

The health communication and education in the transfusion room should adopt the method of parent education mainly, supplemented by the patients' education. The nurses should spread the leaflets to the patients when injecting, and make oral health communication and education, and relevant notices about the venous transfusion. The nurses should make hand-hand takeover with the parents and orally explanations. Inform the parents of the pressed and held part, the method, the strength and time after withdrawal of needle, making sure that the patients leave the transfusion room after they stop bleeding. Install TV in the transfusion room, broadcast the health education prescriptions in the rotating form by the multi-media, and intersperse the broadcast with the cartoons and music the children love, teaching through lively activities.

\section{Conclusion}

In the safety management of the transfusion in pediatrics outpatient, the author deeply realizes that, with the gradual transformation of modern medical science and social structure, the manager should fully take into consideration the impact brought by the social factors on the nursing team, make good use of the advantageous factors and change the unfavorable factors by active means. Pediatrics transfusion safety should not stay in the stage of nursing operation, legal education and compliance with the system and rules, but what is more important is how to meet the needs of patients and their parents continuously in physical and psychological aspects, conducting and providing timely psychological assessment and intervention, making the patients feel that infusion treatment process is a continuous treatment service process. At the same time, strengthen the nurses' self-cultivation, enhance the operation skills, and improve the service awareness and communication skills, so the nurses can move forward in the atmosphere of strictness, harmony and progressiveness. Only by the balance between these two aspects can complete the transfusion nursing work safely, effectively, and efficiently.

\section{References}

1. Wu P. Causative analysis on communication barrier between patients and nurses and its countermeasures. Chinese Nursing Research. 2004;18(5):932-935.

2. Zheng $\mathrm{YH}$. The causes and countermeasures of nurses being attached in transfusion rooms. Nursing and Rehabilitation Journal. 2005;4(3):229-231.

3. Xi SH. The importance of coordinating relations between emergency nurses and patients. Journal of Nurses Training. 1997;12(5):176-177.

4. Shu LX. Analysis and countermeasures of causes of reasons for actual quantity of pediatric intravenous drug and dosage of the doctor's advice. Journal of Nurses Training. 2002;17(11):856-857.

5. Ling $Y$. The analysis of the causes of pediatric outpatient infusion conflicts between nurses and patients. Zhejiang Journal of Preventive Medicine. 2008;20:11-13.

6. Yin L, Wang J, Qiang XY. The problems existing in the pediatric health education and countermeasures. Maternal and Child Health Care of China. 2006;15(2):62-66. 